(2) Open Access Full Text Article

ORIGINAL RESEARCH

\title{
A qualitative study of patient perspectives related to glucocorticoid therapy in polymyalgia rheumatica and giant cell arteritis
}

This article was published in the following Dove Press journal: Open Access Rheumatology: Research and Reviews

\author{
Elizabeth Hoon' \\ Carlee Ruediger ${ }^{2,3}$ \\ Tiffany K Gill ${ }^{2}$ \\ Rachel J Black ${ }^{2,4}$ \\ Catherine $\mathrm{L} \mathrm{Hill}^{2-4}$ \\ 'School of Public Health, University of \\ Adelaide, Adelaide, SA 5000, Australia; \\ ${ }^{2}$ Adelaide Medical School, University of \\ Adelaide, Adelaide, SA 5000, Australia; \\ ${ }^{3}$ Rheumatology Unit, The Queen \\ Elizabeth Hospital, Woodville, SA 50II, \\ Australia; ${ }^{4}$ Rheumatology Unit, The Royal \\ Adelaide Hospital, Adelaide, SA 5000, \\ Australia
}

Correspondence: Catherine L Hill Adelaide Medical School, University of Adelaide, Level 7, SAHMRI, North Tc, Adelaide, SA 5000, Australia

Email Catherine.Hill@sa.gov.au
Objective: To determine patient experiences of glucocorticoid (GC) therapy in polymyalgia rheumatica (PMR) and giant cell arteritis (GCA).

Methods: Patients with a diagnosis of PMR or GCA were invited to participate in this qualitative study that used focus groups to explore: symptoms onset, process of diagnosis, treatment, adverse effects (AEs), and ongoing condition/s management. Data were transcribed verbatim and a "framework" approach was used for analysis and interpretation.

Results: Fourteen patients participated. Weight gain, changes in face and neck shape, and bruising were commonly reported and impacts of these AEs on quality of life were highlighted. Dealing with uncertainties associated with long-term experiences of the condition/s and cycles of GC treatment were raised as were workload demands for patients in managing both the condition and other people's expectations and recommendations related to GC therapy.

Conclusion: These findings demonstrate that the patient experience of GC use is poorly captured by usual physician monitoring for GC AEs. These findings suggest that development of a patientreported outcome instrument for inflammatory conditions treated with GCs is required.

Keywords: patient experience, polymyalgia rheumatica, giant cell arteritis, adverse effects, glucocorticoid therapy

\section{Introduction}

Polymyalgia rheumatica (PMR) and giant cell arteritis (GCA) are relatively common rheumatic conditions occurring in older people ${ }^{1}$ and while the relationship between these two conditions is not clearly established, approximately $15 \%$ of the patients with PMR also develop GCA and around $50 \%$ of those with GCA also have associated PMR. $^{2}$ Glucocorticoids (GCs) are the current mainstay of therapy for both PMR and GCA with excellent efficacy. However, GC therapy is associated with many potential adverse effects (AEs). In order to minimize these AEs when treating PMR and GCA, the aim is to use the lowest dose possible for the shortest duration necessary to control disease and prevent relapse. ${ }^{3}$ However, in clinical practice, patients will often require GC therapy for two or more years, ${ }^{4-7}$ and this accounts for up to a third of elderly people who are taking long-term low dose corticosteroids. ${ }^{4}$ Thus, although the overall prognosis of PMR itself can be regarded as good, the inherent and predictable AEs of the GC treatment contribute to a significant health burden.

Some GC AEs, such as fractures, diabetes, and hypertension, are easy to measure and are known to have a significant impact on patients in terms of quality 
of life, direct, and indirect medical costs. ${ }^{5}$ However, other frequent AEs are more difficult to measure and their impact on the quality of life is less understood. It is likely that patients with differing demographics and diagnoses will have different experiences of the beneficial and AEs of GC use. Little is known about how these effects impact on people with PMR and GCA. ${ }^{6,7}$

This study contributes to a larger body of work driven by the OMERACT (Outcome Measures in Rheumatology Clinical Trials) Glucocorticoid Special Interest Group (GC SIG), which aims to develop a patient-reported outcome measure (PROM) for GC therapy. ${ }^{8}$ In this preliminary study, the objective was to explore patient experiences of PMR and GCA, along with their perceptions of GC therapy and any associated beneficial and AEs.

\section{Methods}

\section{Study design}

The overall design for this qualitative study drew on a phenomenological approach emphasizing the embodied experiences of those people living with PMR and GCA. ${ }^{9}$ This approach assumes that people create meaning through the experience of moving through space and across time. ${ }^{9}$ This non-interventional study used focus groups with patients who had PMR and/or GCA as its method of data collection and a "framework analysis" approach to analyze and interpret the results. ${ }^{10}$

\section{Sample and recruitment}

Patients from rheumatology clinics at two Australian tertiary hospitals, The Queen Elizabeth Hospital and the Royal Adelaide Hospital, were invited by letter and information sheet $(\mathrm{n}=79)$ to participate in the study. Informed consent was gained via the completion of a signed consent form prior to participation in the focus group. There were 14 participants and of these, 12 attended one of the four focus groups (see details in Table 1) with an additional two participants unable to attend on the day, subsequently interviewed individually, by phone. Eligibility criteria for participation were; being at least 18 years old, able to communicate in English, and currently under the care of one of the hospital clinics for PMR or GCA. Given that the incidences of these conditions increase with age (peaking between 70 and 80 years) and women are twice as likely as men to be affected ${ }^{11}$ the researchers anticipated that the demographic profile of participants would tend to be older
Table I Participant characteristics

\begin{tabular}{|l|l|l|l|l|}
\hline ID & Age & Sex & $\begin{array}{l}\text { Year } \\
\text { diagnosed } \\
\text { with PMR }\end{array}$ & $\begin{array}{l}\text { Current } \\
\text { dose of } \\
\text { glucocorticoids }\end{array}$ \\
\hline Focus group I & $65-74$ & Male & 2000 & 0 \\
Focus group I & 75 yrs + & Male & 2006 & 3 \\
Focus group I & 75 yrs + & Female & 2008 & 1 \\
Focus group 2 & $65-74$ & Male & 2010 & 3 \\
Focus group 2 & $65-74$ & Female & 2014 & 0 \\
Focus group 2 & $65-74$ & Female & 2010 & 0 \\
Focus group 3 & 75 yrs + & Female & 2004 & 8 \\
Focus group 3 & $65-74$ & Female & 2012 & 0 \\
Focus group 3 & $65-74$ & Female & 2004 & 3 \\
Focus group 3 & $45-64$ & Female & 2011 & 0 \\
Focus group 4 & $65-74$ & Male & 2011 & 0 \\
Focus group 4 & $65-74$ & Male & 2010 & 0 \\
Interview 1 & $65-74$ & Female & 2012 & 5 \\
Interview 2 & $65-74$ & Female & 2013 & 0 \\
\hline
\end{tabular}

and female, although inclusion of some men and a range of ages were identified as important in sample recruitment.

\section{Data collection}

Focus groups, following a semi-structured script (see Table S1) were facilitated by an experienced qualitative research fellow (EH) and a clinical trails researcher (CR) with clinical experience in rheumatology. Neither had a clinical relationship with the participants. Focus groups lasted approximately 90 mins and were conducted away from the hospital setting at Arthritis South Australia. This is a charitable organization that works locally to empower people living with arthritis and related conditions, to achieve the best possible quality of life through advocacy, education, self-management, and the support of research. Semi-structured interviews, following the same script as the focus groups, were conducted with two further participants who were unable to attend the focus groups. With consent, focus groups and interviews were audio recorded for later transcription. The requirement for confidentiality of content discussed at each focus group was stressed by the facilitators (and covered in the study information sheet and consent form). Themes discussed were: onset of symptoms, process of diagnosis, treatment, AEs of treatment, and ongoing management of their condition/s. Prior to a focus group, participants were invited to complete a brief questionnaire including demographic data, disease duration, comorbidities, current GC dose, duration of GC dose. Reflexive notes, including impressions of data collection and emergent themes, were used by the researchers in analysis and interpretation. 


\section{Analysis}

All focus group and interview data were transcribed verbatim and a framework analysis ${ }^{10}$ approach was used to analyze and interpret the qualitative data. Framework analysis was used as it allowed for both inductive and deductive analysis. The researchers were interested in exploring specific experiences tied adverse events (AEs) associated GC therapy (deductive approach) while also being open to gaining new understandings about subjective experiences and attitudes associated with GC use (inductive approach). The Nvivo10 software was used to code, and refine patterns and relationships in the data. Analysis began with familiarization of the data individually by both clinical and nonclinical researchers. Open coding of the transcripts was used to account for multiple perspectives and themes (related to emotions, values, and experiences) while a specific theme tied to AEs was also examined as this had been a topic of interest in the design of the study. As a team, four of the five researchers then met face-to-face to compare their individual open and specific coding of separate focus group transcripts and to begin testing and refining an agreed coding framework. Patterns and relationships were used to develop and apply a working thematic framework for all transcripts. Table S2 outlines the way coding developed to identify and test these themes. Potential major themes that were supported by data from multiple participants (data triangulation) were then discussed by the researchers to form a consensus on the themes to be reported. In the interpretation stage triangulation of the findings with other analyses were used to test the rigor of the findings.

\section{Results}

\section{Patient sample characteristics}

Of the 14 participants, 1 was aged less than 65 years, 10 were between 65 and 74 years, and 3 were over 75 years. Participants were most likely to be women $(n=9)$ and all but two reported having at least one other health condition. Diagnosis ranged from 2000 to 2014, and six were currently on GC therapy, see Table 1.

\section{Themes of findings AEs of GC therapy}

While a few participants $(n=3)$ reported that they had not experienced any AEs associated with GC treatment, the majority of participants reported at least some, with a wide range identified (see Table 2). A key characteristic of these data on AEs was the prominence of those associated with appearance, with bruising, face and neck shape, and weight gain frequently cited. As the quotes demonstrate, the impact of AEs on participants' everyday lives and their wellbeing was an important aspect of their descriptions. For example, when participants talked about bruising, several dimensions of their effects were identified, not only pain and unsightliness, but also the impact of bruises on both their workplace and personal relationships. The example quotes (Table 2) highlight the emotive language used to describe difficult everyday interactions that resulted. In relation to weight gain, language such as "hate myself", and "I was hungry all the time" were used to describe how some participants felt about this AE. It is of note that these descriptions were described in the context of high GC doses and that the participants perceived that AEs were dose dependent. Further, the AEs that were described (see Table 2) tended to occur after an initial positive treatment effect.

\section{Managing uncertainties}

Across multiple analysis nodes, an underlying theme of managing uncertainties related to the condition/s and treatment was commonly expressed. The uncertainties of living with the condition long term, dealing with cycles of GC treatment, managing the warning signs of flares, and distinguishing symptoms of the condition from other health issues, were all raised. For example, when discussing how he selfmonitored for symptoms when reducing his GC dose, a male participant also inferred a level of uncertainty in relation to how his body (his system) responded, (quote 1, Table 3). Another participant noted that: I get aches and pains and I think, oh, is that [PMR] coming back again? A further participant, in recounting the process of tapering the GC dose, recognized that "twinges" may not be related to his condition, but rather other everyday activities. In response to this uncertainty, the participant reported that he increased his GC dosage slightly (quote 2, Table 3 ).

\section{Managing other people's expectations and recommendations relating to GC therapy}

A third prevailing theme in the data related to the expression of distrust and concern about GC therapy. Specifically, participants from all four focus groups reported that both clinicians and family and friends had conveyed concern about GC therapy. Participants also explained how they had managed this distrust. For example, following diagnosis of PMR and commencement of GC treatment by a replacement clinician, a participant's usual GP refused to continue to prescribe the therapy (quote 3, Table 3). The participant's account 
Table 2 Summary of findings related to side effects of Glucocorticoids therapy, including examples of quotes

\begin{tabular}{|c|c|c|}
\hline $\begin{array}{l}\text { Nodes: Side effects } \\
\text { |Side effects GC| }\end{array}$ & $\begin{array}{l}\text { Number of coding } \\
\text { references }\end{array}$ & Example quotes \\
\hline Bruising & 6 & $\begin{array}{l}\text { Bruising which is quite painful. Bruising - no this is nothing [signalling to bruises on her]. I used } \\
\text { to be black and blue up here. Someone would just bump me. In my lunch break one day } \\
\text { someone knocked me into a pillar. I went back to work and I was black from here down and } \\
\text { everyone at work thought who the hell's beat you up } \\
\text { And } \\
\text { That's what my husband said, people will think l've bashed you up. I used to work for ...... } \\
\text { [retail outlet], and we have a security guard out the front .... He came up to me and he said. } \\
\ldots \text { can I have a word? He said are you all right? }\end{array}$ \\
\hline Face shape & 6 & $\begin{array}{l}\text { The puffiness was a worry, because l'd go and look at myself in the face and I thought, no, that's } \\
\text { not me. That's not me. I mean, my eyes were always puffy }\end{array}$ \\
\hline Neck & 3 & $\begin{array}{l}\text { I had a terribly swollen face, which l've still got. I'm still - and a huge neck, but that was the } \\
\text { huge doses of prednisolone }\end{array}$ \\
\hline Facial hair & I & \\
\hline Weight gain & 4 & $\begin{array}{l}\text { I did put on a bit of weight initially, so I thought I can't do this because I've never been big. I } \\
\text { was bigger than I've ever been. I hated myself. I used to get depressed by the whole thing } \\
\text { And } \\
\text { I can't choose because the weight - there were so many traumatic things. They all sort of rear } \\
\text { their ugly head. The weight initially, so I would eat so healthy I was hungry all the time. } \\
\text { Female: Oh, yes, stimulating the appetite }\end{array}$ \\
\hline Weight loss & I & \\
\hline Diabetes & 5 & Well, see, the prednisolone had played havoc with my diabetes. I ended up on insulin because of that. \\
\hline Immunity & I & \\
\hline Indigestion & 2 & \\
\hline Osteoporosis & 6 & Comments cover risk of osteoporosis as well as having osteoporosis \\
\hline Sleep & 4 & I couldn't sleep. Yeah. I got to bed and couldn't sleep \\
\hline Tiredness/strength & 3 & $\begin{array}{l}\text { Just tiredness all the time and not having any energy. Mainly not the }- \text { I mean, I didn't have } \\
\text { energy to do anything }\end{array}$ \\
\hline
\end{tabular}

highlights the emotive language used by the clinician and the need for him to arrange care by the other GP to overcome this distrust of GCs. Distrust of GC therapy was also reported from family and friends, as shown in quote 4 , Table 3.

Participants reported that they managed distrust expressed by clinicians at the same time as experiencing positive treatment effects themselves (quote 5, Table 3). This theme highlights an additional burden for patients in managing responses and recommendations from both clinicians and others, to their condition and therapy.

\section{Discussion}

This study has provided insights into how GC therapy affects the lives of patients with PMR/GCA. Its findings corroborate results from other qualitative work conducted for the OMERACT 2016 SIG meeting $^{8}$ by identifying a common set of AEs associated with GC therapy. Further, findings emphasized the importance of AEs related to appearance and highlighted how patients' subjective understandings of these may affect their embodied selfidentities and perceptions of personal and work relationships, and thereby their quality of life. By extending our understanding beyond a classification of literal AEs to their extended effects on quality of life, this study may inform the development of a PROM for GC therapy. ${ }^{8}$

The two further dominant themes identified; managing uncertainties related to the condition and GC therapy, including difficulties distinguishing between the impacts 
Table 3 Example quotes for themes of managing uncertainties and other people's responses to GC therapy

\begin{tabular}{|c|c|}
\hline $\begin{array}{l}\text { Themes from nodes and quote } \\
\text { numbers }\end{array}$ & Example quotes \\
\hline \multicolumn{2}{|l|}{ Managing uncertainties } \\
\hline Quote I & $\begin{array}{l}\text { [Referring to GC dose]. if I try and go down a bit more l'll get away with it for probably two or three weeks } \\
\text { and then you might feel a little ache somewhere and you think to yourself, is this because l've gone down, } \\
\text { or is this something new happening to the system? }\end{array}$ \\
\hline Quote 2 & $\begin{array}{l}\text { As I say, one and a half is the lowest l've got down to and within probably two, three weeks I might start to } \\
\text { feel a twinge in the shoulders or something and then you think to yourself, well, is this the poly or what } \\
\text { have I been doing lately? Oh, I was on the roof when the boss [referring to his wife] was down the street, so } \\
\text { she wouldn't see me and you think, oh no, I'll just go up that half a milligram again. }\end{array}$ \\
\hline \multicolumn{2}{|l|}{$\begin{array}{l}\text { Managing other people's responses } \\
\text { to GC therapy }\end{array}$} \\
\hline Quote 3 & $\begin{array}{l}\text { So when I needed a refill - another script when my doctor came back - he was quite annoyed. He said he } \\
\text { hated prednisolone. Used words that doctors don't normally use but l've been going to him a long time. He } \\
\text { wouldn't give them to me. So I then rang up the other doctor and got an appointment with the other } \\
\text { doctor. He put me straight back on them. That's the way we've managed it all the way through. }\end{array}$ \\
\hline Quote 4 & $\begin{array}{l}\text { When my family found out that I was one - well, my sister-in-law found out that I was on prednisolone, she said, oh, } \\
\text { no. }\end{array}$ \\
\hline Quote 5 & $\begin{array}{l}\text { I can recall saying to him "do you have to lower the dose this quick?" [laughs] because I wanted to keep } \\
\text { feeling as good as I was feeling. That's when he explained to me how dangerous it was and how the medical } \\
\text { profession hated it. But he said it's the only one that makes - does the job and makes the people feel better. }\end{array}$ \\
\hline
\end{tabular}

of the condition and the therapy; and managing other people's expectations and recommendations relating to GC therapy, illuminate the particular demands and responsibilities associated with managing PMR and GCA, and their therapy. As Shippee et al, ${ }^{12}$ have argued, patients' "workload" may encompass a wide range of demands, related to their role as a patient (eg, self-care, taking medications, attending appointments) and beyond. Shippee et al, contend that where accumulated workload exceeds the capacities of a patient, their engagement with clinicians, quality of life, health outcomes may be affected. It is therefore important that the design and development of a PROM captures the types of workload burdens reported here, in order to inform clinical practice and effectively support patients. Further specific research would be useful to understand the sense of conflict patients describe when clinicians recommend tapering, while they feel they need ongoing GC therapy.

\section{Limitations}

Although a range of perspectives were gathered, the current study sampled a small number of participants. Despite the sample being drawn from two large public outpatient clinics in the state, participant recruitment was a challenge. This may reflect the age of the target population, and the socioeconomic profile of public patients attending these clinics. As these clinics are major providers of health care for people with these conditions, it is, however, important to conduct and report research that explores the lived experiences of this hard-to-reach population. Given the small sample, the findings may not be representative of all patients with PMR/GCA and $\mathrm{CG}$ therapy. It is also important to note that the number of themes identified may be restricted by the number of participants in the sample. However, there were important commonalities between the findings of this exploratory study and another, which was conducted in the UK and presented at the 2016 OMERACT meeting. ${ }^{8}$ These studies informed the development of a specific research agenda to progress a patient-reported outcome instrument for inflammatory conditions treated with GCs.

\section{Ethics approval and consent to participate}

The study was approved by The Queen Elizabeth Hospital Human Ethics Committee (HREC/14/TQEH/265) with reciprocal ethics clearance from both the University of 
Adelaide and the Royal Adelaide Hospital. Potential participants were invited by letter and information sheet to participate in the study. Informed consent was gained via the completion of a signed consent form prior to participation in the focus group.

\section{Availability of data and material}

The datasets used and/or analyzed during the current study are available from the corresponding author on reasonable request.

\section{Acknowledgments}

The research team wishes to acknowledge the contribution of participants to this study. Arthritis Australia supported this study through funding it through their Grants in Aid Scheme.

\section{Author contributions}

The study was designed by EH, CR, TKG, and CLH. CLH and RJB provided clinical advice on the project. EH and CR collected the qualitative data. All authors were involved in the analysis of data. EH drafted the manuscript and all authors contributed to its review and redrafting. All authors contributed to data analysis, drafting or revising the article, gave final approval of the version to be published, and agree to be accountable for all aspects of the work.

\section{Disclosure}

Through the data collection and analysis period of this study, Elizabeth Hoon was supported by an Arthritis South Australian Florey Research Fellowship. Tiffany K Gill reports grants from Arthritis Australia, during the conduct of the study. The authors report no other conflicts of interest in this work.

\section{References}

1. Ameer F, McNeil J. Polymyalgia rheumatica: clinical update. Aust Fam Physician. 2014;43:373-376.

2. Salvarani C, Cantini F, Hunder G. Polymyalgia rheumatica and giant cell arteritis. Lancet. 2008;372:234-245. doi:10.1016/S0140-6736 (08)61077-6

3. Rheumatology Expert Group. Therapeutic Guidelines: Rheumatology. Melbourne; 2006.

4. Walsh LJ, Wong CA, Pringle M, Tattersfield AE. Use of oral corticosteroids in the community and the prevention of secondary osteoporosis: a cross sectional study. BMJ. 1996;313(7053):344-346. doi:10.1136/bmj.313.7053.344

5. Manson SC, Brown RE, Cerulli A, Vidaurre CF. The cumulative burden of oral corticosteroid side effects and the economic implications of steroid use. Respir Med. 2009;103(7):975-994. doi:10.1016/ j.rmed.2009.01.003

6. Da Silva JA, Jacobs JW, Kirwan JR, et al. Safety of low dose glucocorticoid treatment in rheumatoid arthritis: published evidence and prospective trial data. Ann Rheum Dis. 2006;65(3):285-293. doi:10.1136/ard.2005.038638

7. Hoes JN, Jacobs JW, Verstappen SM, Bijlsma JW, Van der Heijden GJ. Adverse events of low- to medium-dose oral glucocorticoids in inflammatory diseases: a meta-analysis. Ann Rheum Dis. 2009;68 (12):1833-1838. doi:10.1136/ard.2008.100008

8. Black RJ, Robson JC, Goodman SM, et al. A patient-reported outcome measure for effect of glucocorticoid therapy in adults with inflammatory diseases is needed: report from the OMERACT 2016 special interest group. J Rheumatol. 2017;44(11):1754-1758.

9. Starks H, Brown Trinidad S. Choose your method: a comparison of phenomenology, discourse analysis, and grounded theory. Qual Health Res. 2007;17(10):1372-1380. doi:10.1177/104973 2307307031

10. Gale NK, Heath G, Cameron E, Rashid S, Redwood S. Using the framework method for the analysis of qualitative data in multi-disciplinary health research. BMC Med Res Methodol. 2013;13(1):1-8. doi:10.1186/1471-2288-13-1

11. Salvarani C, Cantini F, Boiardi L, Hunder GG. Polymyalgia rheumatica and Giant-Cell Arteritis. N Engl J Med. 2002;347(4):261-271. doi:10.1056/NEJMra011913

12. Shippee ND, Shah ND, May CR, Mair FS, Montori VM. Cumulative complexity: a functional, patient-centered model of patient complexity can improve research and practice. J Clin Epidemiol. 2012;65 (10):1041-1051. doi:10.1016/j.jclinepi.2012.05.005 


\section{Supplementary materials}

Table SI Script used for discussion in focus groups and telephone interviews with PMR and GCA patients

- What were your main PMR/GCA symptoms?

- How did you feel when you were told you needed to go on steroids to manage your PMR/GCA?

- How did the steroid treatment affect you?

- Have you had any side effects when taking these steroids?

- If so, what happens to you and how does this affect you (for instance appearance, mood, sleep, stomach?) and the way you live your life?

- If you have multiple side effects, which side effects matter to you most and why?

- How, if at all, have the side effects changed over time?

- Are there any other issues about managing your PMR/GCA that you think are important but that we haven't covered? 
Table S2 Development of thematic framework

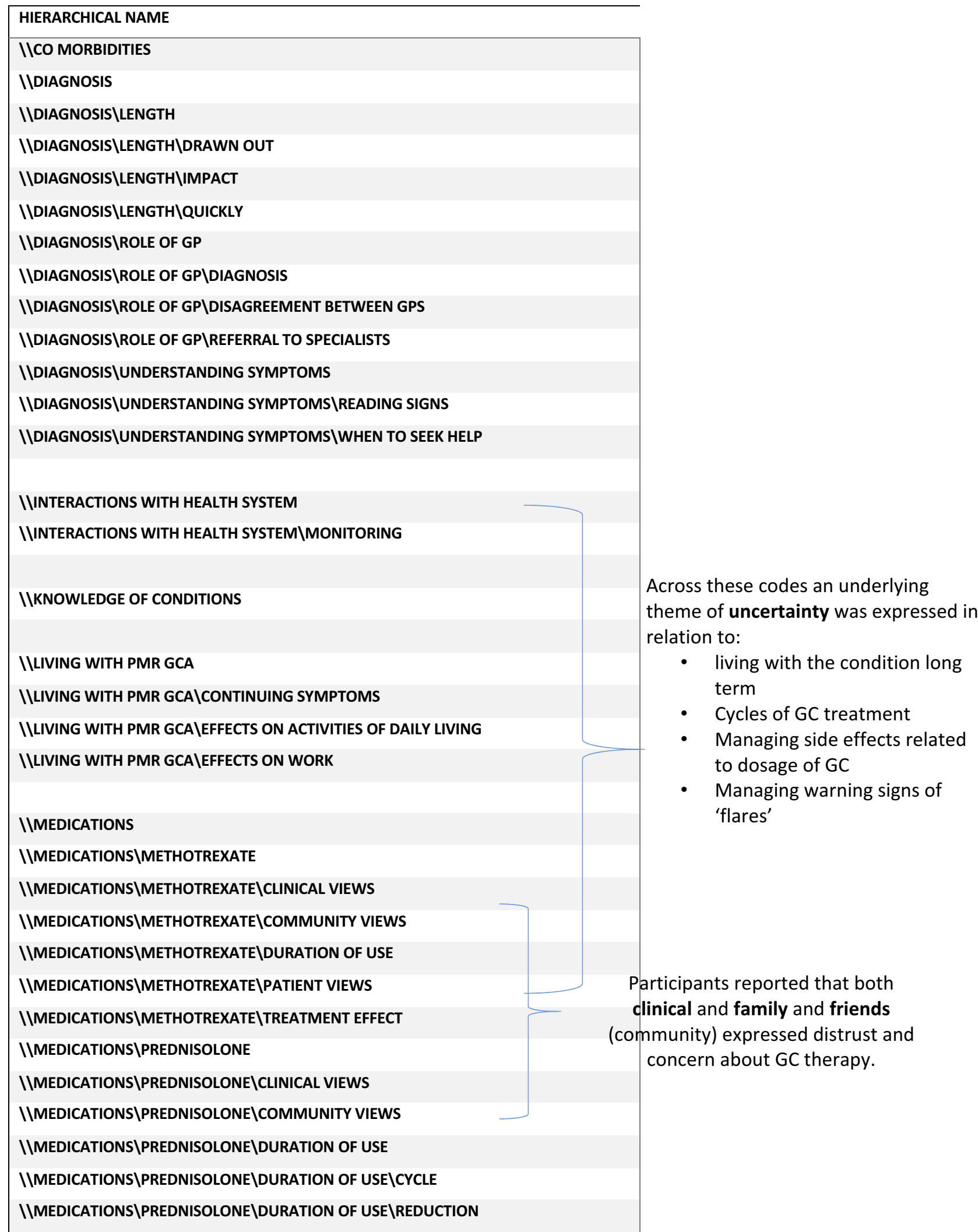


Table S2 (Continued).

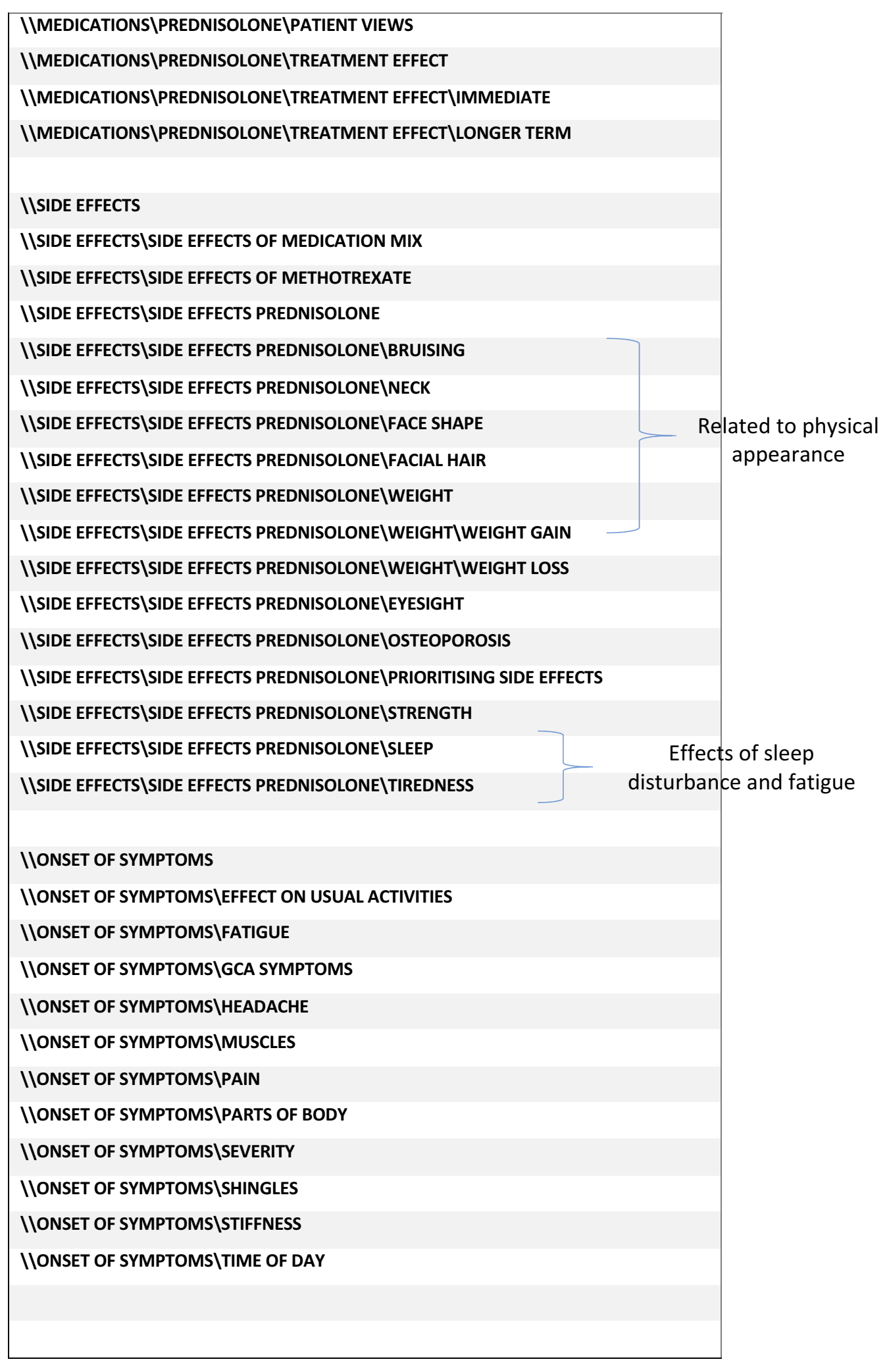




\section{Publish your work in this journal}

Open Access Rheumatology Research and Reviews is an international, peer-reviewed, open access journal publishing original research, reports, editorials, reviews and commentaries on all aspects of clinical and experimental rheumatology in the clinic and laboratory including the following topics: Pathology, pathophysiology of rheumatological diseases; Investigation, treatment and management of rheumatological diseases; Clinical trials and novel pharmacological approaches for the treatment of rheumatological disorders. The manuscript management system is completely online and includes a very quick and fair peer-review system, which is all easy to use. Visit http://www.dovepress.com/testimonials.php to read real quotes from published authors. 